Research Article

\title{
Making the Pitch: Examining Dialogue and Revisions in Entrepreneurs' Pitch Decks
}

\author{
-Clay Spinuzzi, Scott nelson, Keela S. Thomson, francesca lorenzini, Rosemary A. French, \\ Gregory Pogue, Sidney D. BuRback, AND JoEl Momberger
}

\begin{abstract}
Research problem: The question: How Korean entrepreneurs in an entrepreneurship program revised their slide decks for their presentations ("pitches") in response to professional communication genres representing feedback from potential stakeholders in their target markets is examined. Research questions: As entrepreneurs learn to pitch ideas to unfamiliar markets, how do they revise their slide decks for their pitches when interacting with other professional communication genres that represent the concerns of market stakeholders? Specifically, what changes do entrepreneurs make to the claims, evidence, and complexity of arguments in their pitches? Literature review: The professional communication literature demonstrates that the revision process tends to take place in documentation cycles where documents are set in interaction with each other. Yet such revision processes are not studied in detail in existing studies of entrepreneurial pitches in marketing and technology commercialization. Methodology: In this exploratory qualitative study, researchers textually analyzed 14 sets of five related document genres in the archives of an entrepreneurship program. These genres represented a full cycle of activity: application to the program, initial pitches, initial feedback from program personnel, detailed feedback from representative stakeholders in the target market, and revised pitches. Interviews and surveys of program personnel further contextualize the data. Results and conclusions: Entrepreneurs revised their claims and evidence based on their dialogue with their target market. Some of the entrepreneurs altered their slides to make more complex arguments rebutting stakeholders' concerns. These findings suggest that entrepreneurs engage in dialogue with their target markets, but their engagement tends to be guided by tacit, situated experience rather than through an explicit, systematized approach.
\end{abstract}

Index Terms-Communication effectiveness, global communication, knowledge transfer, rhetoric, small-business technology transfer.

\section{INTRODUCTION}

$\mathbf{M}$ arkets are conversations" or dialogues, as the marketing literature tells us [41]. (See also [5] and [39].) In pitching their products or services, entrepreneurs must be able to engage in such market conversations or dialogues with potential stakeholders. A dialogue can be as minimal as a feedback loop where entrepreneurs advance a proposition to representative stakeholders, receive feedback from them, and revise the proposition

Manuscript received November 27, 2013; revised May 02, 2014, July 03, 2014; accepted July 08, 2014.

C. Spinuzzi is with the Department of Rhetoric and Writing, University of Texas at Austin, Austin, TX 78712-1122 USA (email: clay.spinuzzi@utexas.edu).

S. Nelson is with the Department of English, University of Texas at Austin, Austin, TX 78712 USA (email: rscottnelson@gmail.com).

K. S. Thomson, F. Lorenzini, G. Pogue, S. D. Burback, and J. Momberger are with the IC2 Institute, The University of Texas at Austin, Austin, TX 78705-3512 USA (email: kthomson@ic2.utexas.edu; francescaacacia@yahoo. com; gpogue@ic2.utexas.edu; sid@icc.utexas.edu; jgmomberger@gmail.com).

R. A. French is with the Graduate School of Business, The University of Texas at Austin, Austin, TX 78712 USA (email: rfrench@utexas.edu).

Color versions of one or more of the figures in this paper are available online at http:/ / ieeexplore.ieee.org.

IEEE 10.1109/TPC.2014.2342354 based on that feedback-as long as it allows entrepreneurs to bridge different contexts so that they can co-create a solution with those stakeholders. In fact, as Peter Drucker says, the value of an innovative product or service comes from tying together contexts that may be unfamiliar [18]. Within this conversation, one important genre is the pitch, which Clark defines as an oral presentation of an opportunity, delivered to potential stakeholders [11]. But, surprisingly, the research literature on the pitch focuses primarily on its delivery, not on the dialogue with the market's stakeholders, the dialogue from which the pitch emerges. Guidance on the process tends to be tacit. And that is a problem, since the strength of the process-progressively revising the pitch to better connect contexts and offer innovative solutions that span those contexts-can also be its weakness.

For example, let's take $\mathrm{K} 5080^{1}$, a Korean company that has developed a wireless webcam and successfully brought it to market in Korea. K5080 now wants to bring its product to the US market. But to successfully do so, K5080 must prepare a pitch deck (a slide deck that accompanies the oral

${ }^{1} \mathrm{~K} 5080$ and the other entrepreneur names used here are pseudonyms. 


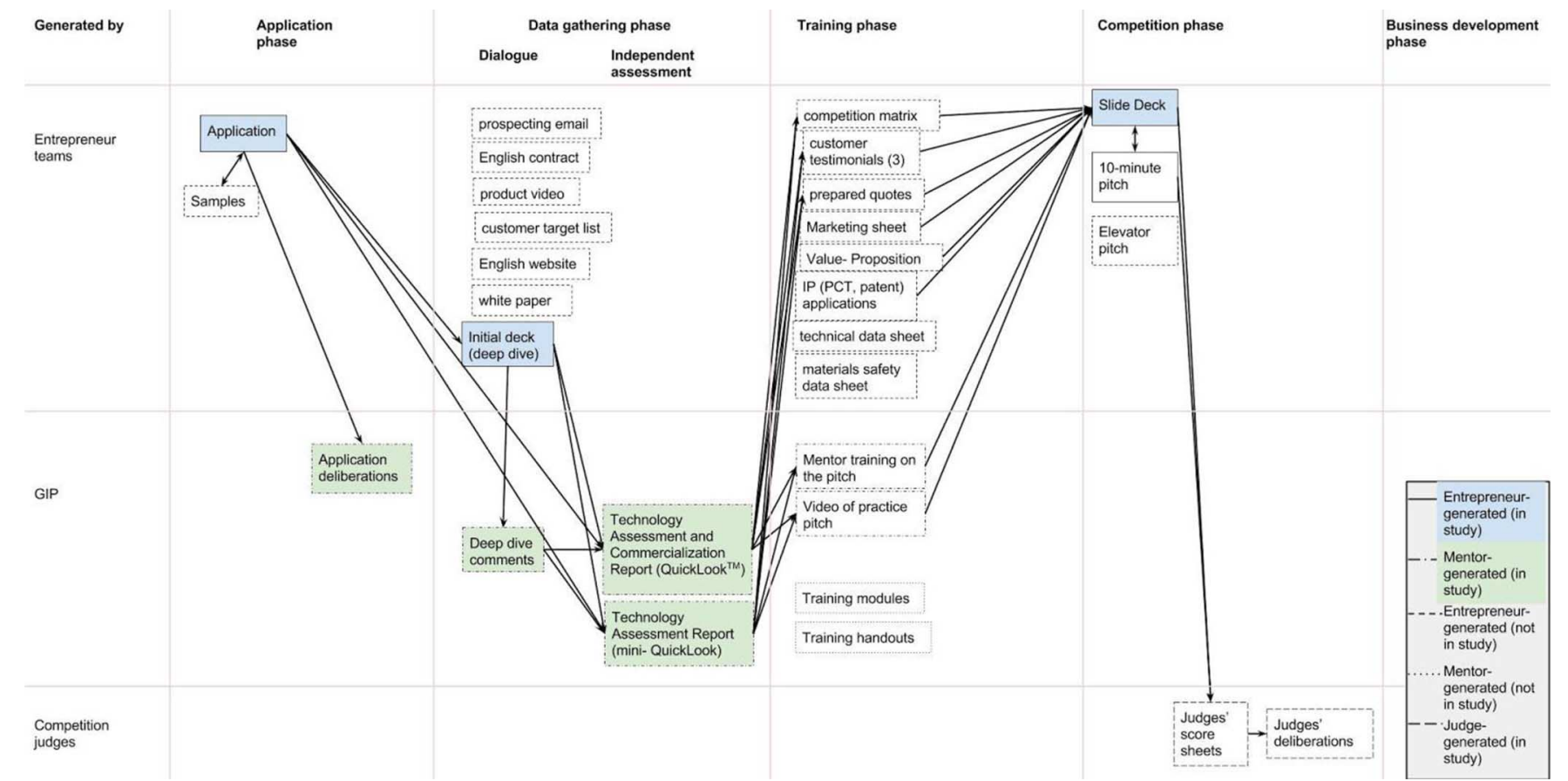

Fig. 1. Genres of the pitch. Various parties generate genres during the five phases of the GIP, with each genre influencing or informing others (arrows).

pitch) that targets a particular kind of stakeholder audience (partners, distributors, licensees, or customers); lays out the benefits of the webcam to that audience; describes its business model, intellectual property status, and development status; and acknowledges and minimizes perceived risks. How does K5080 identify such claims, and how does it make the claims convincing to the selected audience? After all, there are many differences between the "pitcher" (K5080) and the "catcher" (the perceived audience of stakeholders), obviously including differences in Korean and US culture, but also differences in regulatory environment, competitive landscape, and perceived needs. K5080 must engage in dialogue with the market's stakeholders to identify these differences and communicate a persuasive pitch. Otherwise, it cannot find a way to create new value in the new context and there will be no deal.

To learn how to engage in this dialogue, K5080 has entered an entrepreneurship program, the Gyeonggi Innovation Program (GIP). This program involves training and is structured around a pitch competition judged by industry experts, but it is not just an academic exercise. First, the entrepreneurs who enter the competition already have achieved actual (not just academic) success in Korea and many have already begun actual efforts to expand to US markets. Second, during the program, the GIP conducts actual market research for each company's product, and the competition's winners receive actual business development that has historically led to actual deals. The stakes are real, and for these companies, they are high. The companies must learn how to engage in the market dialogue in order to expand; they must be able to pitch. And the GIP, like similar training and development programs, must be able to train them to engage in these dialogues-dialogues that involve a range of professional communication genres, such as pitch decks, technology assessment and commercialization reports, company websites, product descriptions and specifications, written mentor feedback, patents, regulations, and certifications (Fig. 1). Yet, the pitch literature has largely left the process of developing the pitch unexplored: up to this point, no detailed studies of the pitch development process exist.

That research gap led us to ask the following research question: As entrepreneurs, such as K5080, learn to pitch to unfamiliar markets, how do they revise their pitch decks in dialogue with other professional communication genres that represent the concerns of market stakeholders? Specifically, what changes do they make to the claims, evidence, and argumentation complexity in their pitches?

To answer this research question, we qualitatively examined an archive of pitches and related documents from the fifth year of the GIP, and 
we contextualized the process with interviews of program personnel. Below, we survey the literature on pitches, document revision, and document cycles; describe our methodology; describe the results of the study; and discuss findings, limitations, and implications.

\section{LITERATURE REVIEW}

Entrepreneurs, such as K5080, must be attuned to change: as Drucker says, "the entrepreneur always searches for change, responds to it, and exploits it as an opportunity" [18, p. 28]. Defining these opportunities is critical, but it is also difficult. Entrepreneurs must understand the market and the stakeholders operating in it (investors, business partners, distributors, and others who are positioned to both help them and work with them through business arrangements). They must develop arguments that are persuasive to these stakeholders, arguments that culminate in the pitch: an oral presentation of a market opportunity to prospective business partners [11], typically accompanied by a presentation slide deck ("pitch deck").

Below, we first describe our theoretical orientation, then discuss the selection of the literature for review, then overview the relevant literature on revision and document cycles in professional communication studies, then overview the extant literature on pitching and marketing.

\section{Theoretical Orientation Our theoretical} orientation is based in Bakhtinian dialogism [1]-[3] as applied to professional communication research. We use Miller's definition of genre as a typified rhetorical response to a recurring social situation [47], one that represents expectations shared by communicators and receivers in that situation [56]. Genres emerge from social activity and represent, reflect, stabilize, and help constitute that activity, as Smart argues [63]. But as Spinuzzi argues, "they also represent the development and stabilization of worldviews, including the values, ethics, and other humanistic concerns implied in them" [66, p. 41], and "Genre is thus a sort of social memory that its practitioners accept without their explicit recognition that they are doing so," although they "are also dynamic and reshapeable by any speaker for her or his specific utterance" (p. 43). As a set of more or less standard rhetorical moves, a genre addresses certain concerns and avoids addressing others, in a sense embedding a particular logic. By learning a genre, participants learn how to enter a given activity, understanding it in ways the activity's current participants do [56], [64]; in learning to construct a pitch deck, for instance, K5080 also learns the sorts of claims that "catchers" expect "pitchers" to make.

As writers learn new genres, they must revise in response to feedback that is conveyed, often cyclically, through other genres.

\section{Selection of the Literature for Review We} selected two different sets of literature to examine.

To better understand the revision process and how it has been investigated in professional communication research so that we could guide our investigation of the pitch revision process, Author 1 identified landmark studies on revision in the professional communication literature and in related literature such as composition. This literature is vast. In the $1980 \mathrm{~s}$, it was dominated by cognitivist theoretical frameworks, but from the mid-1990s to the present, it has been informed by interpretivist frameworks. Next, Author 1 identified significant research studies representing each framework and consulted overviews such as those by Faigley [19] as welll as Jakobs and Spinuzzi [33] to relate these within a historical progression. Author 1 also examined recent work in professional communication journals and related writing journals, such as the Journal of Technical and Business Communication, Technical Communication Quarterly, and Written Communication as well as relevant conference proceedings, such as SIGDOC and the IEEE International Professional Communication Conference. Finally, Author 1 examined recent professional communication monographs.

To better understand what is already known about the pitch and value propositions, Author 1 performed a Google Scholar search for keywords such as "pitch presentations" and "value proposition" and selected the most relevant results. Author 1 then read the articles, identified relevant citations from those articles, and read the cited articles. Finally, Author 1 identified relevant professional communication literature on proposals.

\section{Research on Revision in Professional} Communication In professional communication studies, revision has long been a focus of research. Below, we discuss two strands of research that shaped our methodology in the present study: the revision process and document cycles. 
Revision Process: Professional communication researchers have studied revision processes since at least the mid-1980s [21], [49], [9], based on earlier work on revision processes in composition [20]. (See Faigley's article [19] for an overview.) Such studies have traditionally examined changes in drafts via textual analysis, often contextualized through observations and interviews.

More recently, revisions have been tracked across electronic versions. For instance, Jones used textual analysis to characterize revisions in Wikipedia articles [34]. Morgan and Zachry have similarly characterized revisions in Wikipedia articles [47]. Professional communication researchers, such as McCarthy et al. [43] and Hart-Davidson et al. [32], have also studied revisions in electronic environments, such as content-management systems, pairing textual analysis with interviews and observations.

As some of the research above implies [22], [32], [34], [43], [47], [49], documents typically do not do work on their own; they are set in interaction with other documents (see the interaction in the GIP process described in Fig. 1). Rather than being decontextualized products, they interact with other documents in document cycles.

Document Cycles: In document cycling, a document undergoes cyclical revision via feedback loops involving other document genres [37], [50], [69], [72] and that provide redundancy and accountability [59]. Document cycling enables writers to build on the solutions embedded in previous documents of the same or related genres, increases coherence and accountability, and circulates information to different parts of the organization(s). It can involve different types of revision [15], [37], [51].

We can think of a document cycle as an ongoing dialogue among the entities who produce the component document genres. For instance, as Fig. 1 suggests, K5080 generates documents (the application, initial deck, and final deck) in dialogue with the GIP (which produces the Deep Dive Comments and the Quicklook). In addition, entrepreneur teams, such as K5080, typically compose a pitch deck by consulting genres, such as product materials, sales reports, market data, and previous pitch decks, all of which provide material that the entrepreneur can reuse in the pitch deck.

Document cycling, like revision, has been studied in professional communication since at least 1985, often but not always within the framework of Genre Theory. Researchers have studied document cycles of proposal and grant writing, particularly in terms of how writers have composed and revised to address the needs of multiple stakeholders as represented in ancillary documents (such as [9], [17], [70] and [78]. Document cycles have been studied in other activities as well: Devitt studied tax accounting [16], Varpio studied health care [75], Spinuzzi studied search-engine optimization [65], Swarts studied information technology [69], and Fraiberg studied product development at a high-tech startup [22]. Again, these studies tend to involve textual analysis of documents contextualized by interviews and often observations. They also tend to be exploratory, developed to identify the contextualized problems being addressed by the document genres in a given context-such as the case examined in this study, the highly contingent issue of pitching to different markets.

\section{Research on Pitching and Marketing As}

mentioned in the Introduction, Locke et al. famously declared that "markets are conversations" [41]. Marketing involves not just presenting a product to a new market, but also engaging in a dialogue with a stakeholder in that market, as described by Ballantyne et al. [5]. From that dialogue emerges a value proposition: a claim about the value of that product to potential customers in that particular market [5], [26], [38], [39], [55], [62], [73], [74]. Marketing genres, such as pitches, must address this dialogue with the target market; they must go through a revision process of proposing, learning, responding, and refining claims. Done well, this revision process connects the interests of the pitcher and catcher, resulting in a new co-created value [4], [39], [42].

Yet, the research literature on the pitch has not explored this revision process well. The pitch ties the interests of the "pitcher"-K5080 and other entrepreneurs-to that of "catchers" such as investors, distributors, customers, users, or other market partners. These "catchers" might then examine other materials, such as specific business proposals, as Clark [11] argues. (For professional communication research into business proposals, see Beck and Wegner [7], Broadhead and Freed [9], Convertino et al. [12], Kent-Drury [35], McIsaac and Aschauer [44], Sales [58], and Zachry et al. [78].) Pitches make claims about the value proposition, the target market, and the entrepreneur team. Often, as in the GIP, pitches are performed orally and supported by slide decks, usually generated in PowerPoint (cf. Galbraith et al. [27]). 
As Clark states, the business pitch has not been well studied in the research literature [11]. The extant literature describes how the business opportunity is "talked into existence," as Pollack et al. put it [53], by telling narratives about the opportunity, narratives that include personal, generic, and situational stories [48]. The literature focuses on how these narratives are presented via presentation skills and made persuasive through the presenter's charisma [11], [77] as well as the team's composition and track record [77]. Also important is the presenter's ability to demonstrate accurate, detailed knowledge of various aspects of the pitch and to anticipate and proactively rebut the audience's objections [10], [53].

Such studies have not explored the revision process that leads to that final pitch: the process that develops the narratives, elucidates the team's qualities, and allows the presenter to anticipate and prepare for questions. Even in the wider literature on value propositions, studies are in the exploratory phase, primarily qualitative interview-based studies of value (such as Greenman [30], Kristensson et al. [40], Rencher [54], Rintamaki et al. [55], and Skalen et al. [62]), They do not examine documents or revisions.

This lack of focus on the revision process is problematic for technology commercialization programs and consortia, such as GIP. Such consortia, according to Gibson \& Concelcao, attempt to "shorten learning curves and reduce errors" while "provid[ing] access to regional, national, and international markets, resources, and know-how" [28, p. 745]; cf. [52], [68]. Such programs certainly emphasize understanding markets and developing value propositions that speak to the needs of the catchers. Indeed, these programs typically provide actual market feedback appropriate for the market dialogue that was discussed earlier. For instance, GIP contractors research a target market, identifying and interviewing potential stakeholders, then writing results in the form of what Cornwell calls a Quicklook [14], a type of technology assessment and commercialization report that articulates market feedback. But when they help entrepreneurs formulate their arguments and revise them to address market feedback, programs, such as the GIP, typically provide tacit, context-based support rather than explicit, systematic support. At the GIP, pitch decks and associated genres are described in templates; instructions on how to conduct the dialogue are conveyed through a team of mentors with different backgrounds, specialties, and experiences. Furthermore, programs, such as GIP, tend to take on entrepreneurs operating in many different sectors, pitching to markets with differing regulatory constraints, competitive landscapes, business developments cycles, and margins; this wide variation makes it difficult to systematize pitch development and, consequently, the training process emphasizes contingencies and draws heavily on the situated judgment of the mentors.

To address this question of pitch revision, we applied the methodological approach of contextualized textual analysis that has been used so effectively in professional communication research.

\section{MetHodologY}

In this section, we describe how we collected and analyzed the entrepreneurs' pitch documents to understand how these documents' arguments changed over the course of the program, particularly in response to dialogue with the market stakeholders. This methodology allowed us to answer our research question: As entrepreneurs learn to pitch to unfamiliar markets, how do they revise their pitch decks in interaction with other professional communication genres that represent the concerns of market stakeholders? Specifically, what changes do they make to the claims, evidence, and argumentation complexity in their pitches?

This section starts with our choice of research methodology, then describes the research site and participants, data collection, data storage and reduction, data analysis, and how we ensured the credibility and trustworthiness of the data.

Choice of Research Methodology As discussed before, we followed the paradigm of research that is dominant in professional communication studies of genre, revision, and document cycles. This study is exploratory and limited, but it also appears to be unique in the literature on the pitch because it provides the first detailed glimpse into the pitch's revision process.

Since this research sought to explore a process that had been underexplored, we used an inductive coding approach, since we have other exploratory studies that involve analyzing documents and contextualizing them with interviews (such as Haas and Witte [31], Schuster and Propen [60], and Winsor [76]).

Research Site and Participants To understand how pitch arguments evolve through dialogue, the first author sought a repository of draft and final pitch documents that could be textually analyzed. 
Understanding that such document genres operate within document cycles, the first author also sought a repository that included other genres that were in dialogue with the pitches. In addition, the first author sought participants who could provide the context and history of the pitches in the repository through interviews. Both of these conditions were satisfied by the Gyeonggi Innovation Program, a program run by the IC $^{2}$ Institute, which had archived sets of pitch genres and which allowed interviews with the program director and mentors.

The first author recruited 13 GIP personnel through the $\mathrm{IC}^{2}$ Deputy Director. These GIP personnel included the current and former GIP directors, eight business analysts, two business development specialists, and a presentation trainer. As Table II indicates, six of these participants provided background interviews, three provided interviews about their deliberations on program applications, and six responded to surveys. The second author joined the study to assist in data collection, perform coding, and assist in analysis. Authors 3-8 were affiliated with the research site in various capacities during all or portions of the research project; for this study, Authors 3-5 assisted with data collection and Authors 6-8 provided introductions as well as member checks.

This study was declared exempt by the authors' Institutional Review Board.

For this study, researchers examined a repository of documents from the fifth year of the GIP that represents each stage of the process (Table I). All documents were stored in Basecamp, a web-based project-management system that contains the documents of 253 teams across five years of the GIP's history.

Researchers also gathered contextual data, such as interviews with mentors, training documents, and information on professional background (Table II). These contextual data allowed the researchers to better understand the purpose of the GIP and the training events it offered, the document cycle in which the entrepreneurs developed their documents, the training and documents to which the entrepreneurs responded, and how GIP personnel understood the entrepreneurs' challenges when making pitch arguments.

How Data Were Collected We collected the following data: archives, background interviews, deliberation interviews, and internal surveys.
Collecting Archives: Researchers selected the documents of 14 of the 25 semifinalists in the competition's fifth year (2012) (K5006, K5013, K5016, K5043, K5077, K5080, K5084, K5106, K5117, K5187, K5141, K5157, K5201). These semifinalists were selected because they represented reasonably successful pitches and because their document sets contained a complete set of five types of documents: the applications to the program (which represented the entrepreneur's initial representation of the innovation and its value proposition), the initial deck (which the entrepreneur team usually developed based on the program's template and which served as a rough draft for the final deck), the Deep Dive comments (where analysts responded to the initial deck by assessing the entrepreneur team's product), the Quicklook (a report-also known as the Technology Assessment and Commercialization Report-examining a potential commercialization market, authored by GIP investigators who had been trained in The University of Texas at Austin's Master's of Science in Technology Commercialization program), and the final deck (which represented the entrepreneur's post-training representation of the innovation and its value proposition). These generic sections imply particular types of arguments: for instance, the slide decks require sections describing the business model, markets, and competition, leading teams to make claims related to each. See Table I and Fig. 1.

Collecting Background Interviews: To better understand the process, Authors 1, 3, 4, 5, and 6 conducted semistructured retrospective interviews with the director (P1) and five mentors (P2-P6) in the GIP, focusing on pitch criteria, pitch genres, and cultural differences. Interviews took between 38-90 minutes. The interview questions are listed in Appendix A.

Collecting Deliberation Interviews: Author 1 conducted retrospective interviews with three key personnel involved in deliberations (P1, P7, P8). The interviews took between 10 and 26 minutes. Interview questions are listed in Appendix B.

Conducting an Internal Survey: Author 1 circulated an internal survey with 12 GIP personnel, resulting in 6 responses (for a 50\% response rate). Interview questions are listed in Appendix C.

In Table II, participants and data were collected from them. P3's background interview was not recorded due to equipment failure, but was reconstructed from Author 3's detailed notes. 
How Data Were Stored, Coded, and Reduced After collecting the data, researchers transcribed all observational notes and interviews and converted documents to separate statements to be coded.

Paraphrasing and Transcribing Interviews: The authors initially paraphrased interviews, and then transcribed parts critical to the emerging analysis. Paragraph breaks represented changes in speakers. In all, researchers generated 719 interview entries (paragraph-separated units).

\section{Converting Archived Documents: Author 2} segmented the document materials from Table II into what Saldana calls stanzas [57]: sentences in written materials, visuals (such as photos, figures, and graphs), and slides (in slide decks). In all, researchers generated 8645 stanzas. Author 1 then placed all data in a relational database, with tables for participants, interviews, and archives.

Coding Archive Data: Author 2 coded archive data. Coding was nonexclusive: each datum could be assigned multiple codes. (See Appendix D for a list of codes.) Author 2 began coding deductively, using descriptive starter codes [45]. For convenience, we based the starter codes on parts of the argument that are defined in rhetoric studies (Toulmin [71]; cf. Friess [24], [25]): claim, evidence, qualifiers, and conditions of rebuttal. This model provided a point of departure when coding the data, but the framework was somewhat limited in application. Similar to Freeman's [23] rejection of grounds, warrants, and backing as distinct, we found that, in practice, there is a slippage in these terms' applicability. Warrants tend to be unstated, and grounds can be claims that require further support; both would have required different data.

Further, argumentation often involves eliding explicit references to core values and beliefs [29]. As researchers, filling in those missing premises for our participants has the potential for ethnocentrism, as we would be interpreting the syllogistic gaps in Korean participants' arguments. Such a move involves, at best, suppositions from an inexperienced position and, at worst, stereotyping across a diverse and rich culture and subculture. While there are certainly distinct differences between US and Korean business cultures, investigating those is well beyond the scope of this study. Instead, our aim was to only catalogue explicit changes in those parts of arguments expected by US-based audiences to which the Korean entrepreneurs were pitching. As Simosi
[61] has noted, Toulmin developed his approach by focusing on legal argumentation and, thus, the framework must be adapted for the context and delivery method. While the Toulmin method may be used as a guide, definitions of key terms must take into account "a broader context (i.e., macroargument), which should guide the analysis and restructuring of the argument structure" [61].

In open coding [13], Author 2 inductively identified recurrent themes, defined codes based on them, then checked these codes deductively based on these definitions. Author 2 coded to characterize types of arguments, evidence, rebuttals, and reuse across documents in detail.

Reducing Data: In identifying recurrent themes, coding also allowed researchers to reduce the data by focusing on heavily coded data and on data related to key themes.

How Data Were Analyzed To analyze the data, the authors followed these steps:

Analyzing Retrospective Interviews and Surveys: Authors compared interview and survey results to generate a list of GIP expectations, then compared these expectations to the results of the archive analysis.

Analyzing Archives: Authors 1 and 2 used codes to characterize patterns related to claims, evidence, and reuse, then confirmed these patterns by closely examining the documents in Table I for examples of these patterns. Authors 1 and 2 identified shifts in key types of claims (such as claims about the entrepreneur's business, the product, and the market uses of each innovation, as well as the intellectual property status of the innovation and the problems it solves) across the entrepreneur-generated documents (the application, initial deck, and final deck). In this analysis, authors examined whether arguments changed as entrepreneur teams progressed from one document to another. Authors compared these key changes to statements in intervening documents in the document cycle (the Quicklooks and Deep Dive Comments).

\section{Ensuring the Credibility and Trustworthiness of the Data As an exploratory study with an} inclusive coding scheme, this study did not support interrater reliability measures such as Cohen's Kappa. (See [6].) Instead, the authors followed the established approach for this sort of study, which relies on qualitative and interpretive agreement (for example, [60, p. 173]): after Author 2 coded the entire dataset, Author 1 reviewed the dataset, 
TABLE I

Investigated Document GenRes Involved in Developing the Pitch

\begin{tabular}{|c|c|c|c|}
\hline Genre & Description & Generated by & $\begin{array}{l}\text { Approximate } \\
\text { length (in } \\
\text { pages or } \\
\text { slides) }\end{array}$ \\
\hline Application & $\begin{array}{l}\text { A GIP-supplied form filled out in } \\
\text { English by Korean entrepreneurs } \\
\text { applying to the program. Includes } \\
\text { sections: technical description, } \\
\text { intellectual property status, and } \\
\text { development status. }\end{array}$ & $\begin{array}{l}\text { Entrepreneur } \\
\text { team }\end{array}$ & 2 pages \\
\hline Initial decks & $\begin{array}{l}\text { For describing entrepreneurs' } \\
\text { technology to Deep Dive analysts. } \\
\text { Usually based on a GIP-supplied } \\
\text { template. } \\
\text { Includes sections: technology } \\
\text { description, development status, } \\
\text { benefits, IP status, business model, } \\
\text { markets, market interest, competition, } \\
\text { risks and barriers, and team status. }\end{array}$ & $\begin{array}{l}\text { Entrepreneur } \\
\text { team }\end{array}$ & 20 slides \\
\hline $\begin{array}{l}\text { Deep Dive } \\
\text { comments }\end{array}$ & $\begin{array}{l}\text { For determining whether this } \\
\text { technology is ready to be } \\
\text { commercialized. Responds to the } \\
\text { initial deck. Often based on a GIP- } \\
\text { supplied template, but some are free- } \\
\text { form notes. }\end{array}$ & $\begin{array}{l}\text { GIP analysts } \\
\text { with } \\
\text { entrepreneur } \\
\text { team input }\end{array}$ & 4 pages \\
\hline $\begin{array}{l}\text { Quicklook® } \\
\text { (Technology } \\
\text { Assessment and } \\
\text { Commercialization } \\
\text { Report) }\end{array}$ & $\begin{array}{l}\text { For determining whether this } \\
\text { technology has a good chance of } \\
\text { commercialization in the targeted } \\
\text { market. Based on a GIP-supplied } \\
\text { template, generated by contractors } \\
\text { who had been trained in this genre. } \\
\text { Includes sections: executive } \\
\text { summary, technology description, } \\
\text { potential benefits, development } \\
\text { status, status of intellectual property, } \\
\text { competitors and competing } \\
\text { technologies, potential commercial } \\
\text { markets, potential challenges, } \\
\text { potential opportunities, } \\
\text { recommendations, next step } \\
\text { checklist, and interview notes (from } \\
\text { interviews with people working in the } \\
\text { target market), as well as research } \\
\text { notes. }\end{array}$ & $\begin{array}{l}\text { GIP } \\
\text { contractors }\end{array}$ & 20 pages \\
\hline Final decks & $\begin{array}{l}\text { For supporting presentations by } \\
\text { entrepreneurs to potential US market } \\
\text { partners. Based on the initial deck. } \\
\text { Includes sections: technology } \\
\text { description, development status, } \\
\text { benefits, IP status, business model, } \\
\text { markets, market interest, competition, } \\
\text { risks and barriers, and team status. }\end{array}$ & $\begin{array}{l}\text { Entrepreneur } \\
\text { team }\end{array}$ & 20 slides \\
\hline
\end{tabular}


TABLE II

Participants AND DATA COLleCted From THem

\begin{tabular}{|c|c|c|c|}
\hline Participant & $\begin{array}{l}\text { Background interview } \\
\text { (duration in minutes) }\end{array}$ & $\begin{array}{l}\text { Deliberation interview } \\
\text { (duration in minutes) }\end{array}$ & $\begin{array}{l}\text { Internal } \\
\text { survey }\end{array}$ \\
\hline $\mathrm{P} 1$ & $I 1.1(90)$ & $\mid 1.2(26)$ & \\
\hline $\mathrm{P} 2$ & $12.1(57)$ & & S2 \\
\hline P3 & |3.1(--) & & S3 \\
\hline $\mathrm{P} 4$ & $14.1(57)$ & & \\
\hline P5 & $15.1(18)$ & & \\
\hline P6 & $16.1(38)$ & & S6 \\
\hline P7 & & $17.2(16)$ & S7 \\
\hline P8 & & $18.2(10)$ & \\
\hline $\mathrm{P} 12$ & & & $\mathrm{~S} 12$ \\
\hline $\mathrm{P} 13$ & & & $\mathrm{S13}$ \\
\hline
\end{tabular}

Note: P3's background interview was not recorded due to equipment failure, but was reconstructed from Author 3's detailed notes.

discussing interpretive disagreements with Author 2 , resulting in consensus coding.

In addition, Authors 1-5 conducted detailed member checks with the GIP director, including sharing drafts and conducting follow-up interviews.

\section{RESULTS}

In this section, we discuss the study's results, specifically in terms of how claims, evidence, and argument complexity developed from initial to final pitch decks. We examine the role that dialogue across the documents appeared to be involved in these developments. This section starts with a discussion about the research site and participants, overviews the program's context and general results, then examines changes in claims, evidence, and argument complexity across the documents.

\section{About the Research Site and Participants The Gyeonggi-UT Innovation Program (GIP) is run by the Global Commercialization Group (GCG) of the $\mathrm{IC}^{2}$ Institute, an interdisciplinary research unit at The University of Texas at Austin. GCG facilitates the development of technology-based businesses worldwide by providing experience and training as well as facilitating links to international markets, with the goal of sustained commerce.}

The GIP is a partnership between GCG and the Gyeonggi Small Business Center, structured as a five-phase program ending in a competition. Each year since 2008, it has selected applicants from Gyeonggi Province with promising technologies, provided training and market information for the innovators, and worked with the most promising innovators to help them connect with global target markets. The GIP process includes these phases (with the documents we analyzed in italics):
(1) Application: The GIP receives approximately 200 English-language applications from entrepreneurs in the province, of which 50 are selected as quarterfinalists for the competition. Applications describe the entrepreneurs' technical innovations.

(2) Data gathering: This phase is broken into two components: a dialogue between GIP managers and entrepreneurs, and an independent assessment of the market's interest in the innovation.

(i) The GIP conducts "Deep Dives" (technology assessments) with each entrepreneur. In these Deep Dives, the team mock-pitches to GIP analysts, using an initial deck that is typically based on the GIP's PowerPoint template. The entrepreneur also answers the analysts' questions and takes the analysts on a tour to see the technology in action. Afterwards, the analysts write Deep Dive comments.

(ii) Experienced GIP contractors then write Quicklooks, assessing how well each technology can be commercialized in the target market(s). These reports are typically about 20 pages long and recommend a "go" or "no go" for the specified market as well as actual quotes and other market data from stakeholders in that market. Based on these Quicklooks, the GIP selects 20-25 semifinalists to proceed to the final competition.

(3) Commercialization and pitch training: The GIP program trains entrepreneurs in various 
topics related to technology commercialization and effective pitch communication through classroom settings and individual mentoring. (Program training is ongoing and overlaps with other program phases.)

(4) Competition: The semifinalists pitch to a panel of competition judges, using a final deck based on their initial deck but developed to address the Deep Dive comments and Quicklook concerns. Of the 25 semifinalists, 12-15 finalists are selected for extensive business development support in international markets provided by the GIP team.

(5) Business development: The finalists work with GCG business mentors to identify companies that may wish to purchase, license, or assist in the commercialization of their product.

These phases are accompanied by a large set of document genres, including applications, reports, comments, deliberations, and presentations, which are generated by the entrepreneurs themselves, the GIP, and competition judges (Fig. 1).

The study's participants included the current and former GIP directors, eight business analysts, two business development specialists, and a presentation trainer. As Table II indicates, six of these participants provided background interviews, three provided interviews about their deliberations on program applications, and six responded to surveys. Of the 13 participants, ten were male and three were female; 12 of the 13 were native English speakers, but the 13th had excellent English proficiency. All had substantial experience in entrepreneurship, including extensive contacts in various industries.

We began this paper by describing how K5080 developed its pitch for the global market. In K5080's pitch, we saw definite development: K5080 qualified its claims, provided rebuttals to concerns, and brought in new evidence to support the claims. In this case, the training seemed to be a success. But is $\mathrm{K} 5080$ a typical case? Below, we first discuss the general feedback that GIP personnel gave us about the context and results of the program. Then, we examine the entrepreneurs' documents in terms of how their arguments evolved between the initial and final decks.

Program Context and General Results According to interviews with the GIP director and mentors, the entrepreneur teams operate in a specific domestic environment that has not prepared them for making commercialization pitches in international markets, and in the US market in particular. Consequently, the interviewees described at least four difficulties these entrepreneurs faced in making these pitch arguments: 1) identifying and characterizing a specific target market, 2) expressing benefits for that market (including relieving problems faced in the current market), 3) describing an appropriate business model for producing those benefits, and 4) supplying evidence for their arguments above.

\section{Identifying the Market: The interviews with GIP} personnel suggested that entrepreneurs had to overcome two hurdles. One was that of understanding a market in a different culture. The second was that of understanding an unfamiliar market.

Let us take the second one first. Although the difference in cultural context was an obvious hurdle, it was only one of many having to do with understanding an unfamiliar market. Entrepreneurs were specialists in their technological innovations-wireless webcams, public-address systems, power supplies, and new techniques for tinting class. But they had to learn about a given market in order to determine how (or whether) their innovations could solve an existing problem or create a new opportunity in that market. Who in this market would need a wireless webcam? What features does this webcam have that could provide new opportunities in this market? What regulatory and certification barriers might stymie those opportunities for this market? To discover such problems and opportunities, these entrepreneurs-like any entrepreneurs-had to engage in dialogue with market stakeholders to find out.

With that in mind, the second hurdle, that of approaching a different culture's market, is different in degree but not necessarily in kind. We want to avoid broadly characterizing the logics or understandings of entire cultures, which we believe to be an overly reductive way of understanding such differences, especially in a country as globally connected and rapidly changing as Korea. (For an extended example of the cultural contradictions in one Korean company, see Bjerregard and Jonasson's recent ethnography [8].) But we can characterize some of the differences in the domestic business environment in which entrepreneurs, such as K5080, operate, based on our interviews with GIP personnel and some of the published literature on the Korean market. Small and medium businesses in South Korea, although formally independent, tend to function as subsidiaries of 
TABLE III

Slide Additions And Deletions by Slide Title

\begin{tabular}{|c|c|c|}
\hline Project & Added Slides (titles) & Deleted Slides (titles) \\
\hline K5006 & & "Presentation Outline" \\
\hline K5013 & $\begin{array}{l}\text { "Competition Cont'd" } \\
\text { "Competition Cont'd" } \\
\text { "Potential Challenges (Quicklook report by } \\
\text { UT)" }\end{array}$ & \\
\hline K5016 & "Thank you very much for your attention" & \\
\hline K5043 & & \\
\hline K5077 & "FDA Regulation" & $\begin{array}{l}\text { "Company Name" } \\
\text { "2013" (+ Korean characters) }\end{array}$ \\
\hline K5080 & $\begin{array}{l}\text { "Appendix. Potential Opportunities" } \\
\text { "Appendix: Q\&A 1" } \\
\text { "Appendix: Q\&A 2" } \\
\text { "Appendix: Leaflet" }\end{array}$ & $\begin{array}{l}\text { "Team Status 3" } \\
\text { "Appendix. Specifications " }\end{array}$ \\
\hline K5084 & $\begin{array}{l}\text { "Technology Description" } \\
\text { "Competition" } \\
\text { "SWOT Anaysis" }\end{array}$ & \\
\hline K5106 & & "Markets" \\
\hline K5117 & "SMB Market Interest" & "[Product] Dashboard" \\
\hline K5119 & "Competition" & \\
\hline K5141 & "7. Competition" & \\
\hline K5157 & $\begin{array}{l}\text { "Company \& Product Overview" } \\
\text { "Company \& Product Overview" } \\
\text { "Technology \& Advantages" } \\
\text { "Market Size \& Drivers" } \\
\text { "Go-To-Market Strategies" } \\
\text { "Go-To-Market Strategies" } \\
\text { "Go-To-Market Strategies" } \\
\text { "Go-To-Market Strategies" } \\
\text { "Go-To-Market Strategies" } \\
\text { "Business Milestones" } \\
\text { "Support Requirements" }\end{array}$ & $\begin{array}{l}\text { "Technology Description" } \\
\text { "Development Status" } \\
\text { "IP Status" } \\
\text { "Business Model" } \\
\text { "Markets" } \\
\text { "Market Size and Structure" } \\
\text { "Market Size and Structure" } \\
\text { "Markets" } \\
\text { "Markets" } \\
\text { "Markets" } \\
\text { "Markets" } \\
\text { "Market Interest" } \\
\text { "Competition" } \\
\text { "Media Files for PnF" } \\
\text { "Team Status" } \\
\text { "Company Achievement" } \\
\text { "Questions?" }\end{array}$ \\
\hline K5187 & $\begin{array}{l}\text { "History" } \\
\text { "Technology Description" } \\
\text { "Technology Description" } \\
\text { "Current Clients" }\end{array}$ & $\begin{array}{l}\text { "Company Name" } \\
\text { "Markets" } \\
\text { "Markets" }\end{array}$ \\
\hline \multirow[t]{2}{*}{ K5201 } & $\begin{array}{l}\text { "Technology Description" } \\
\text { "Technology Description" } \\
\text { "Technology Description" } \\
\text { "Development Status" } \\
\text { "Intellectual Property" } \\
\text { "Business Model" } \\
\text { "Markets" } \\
\text { "Market Interest" }\end{array}$ & $\begin{array}{l}\text { "Equipment Overview" } \\
\text { "Equipment Overview" } \\
\text { "H/W Structure and Features" } \\
\text { "H/W Structure and Features" } \\
\text { "H/W Structure and Features" } \\
\text { "H/W Structure and Features" } \\
\text { "H/W Structure and Features" } \\
\text { "H/W Structure and Features" }\end{array}$ \\
\hline & $\begin{array}{l}\text { "Competition" } \\
\text { "Risks and Barriers" } \\
\text { "Team Status" } \\
\text { "Questions?" }\end{array}$ & $\begin{array}{l}\text { "H/W Structure and Features" } \\
\text { "H/W Structure and Features" } \\
\text { "S/W Structure and Features" } \\
\text { "Operation Management" } \\
\text { "Operation Management" } \\
\text { "Operation Management" } \\
\text { "Operational Management" } \\
\text { "Equipment Overview" } \\
\text { "Equipment Overview" } \\
\text { "Equipment Overview" } \\
\text { "HW Structure and Features" } \\
\text { "HW Structure and Features" } \\
\text { "HW Structure and Features" } \\
\text { "HW Structure and Features" } \\
\text { "HW Structure and Features" } \\
\text { "SW Structure and Features" } \\
\text { "Operation Management" } \\
\text { "Operation Management" } \\
\text { "Thank You..." }\end{array}$ \\
\hline
\end{tabular}


TABLE IV

Selected Examples of Claims That Became More Specific in Final Decks

\begin{tabular}{|c|c|c|}
\hline Project & Initial Deck & Final Deck \\
\hline K5016 & $\begin{array}{l}\text { "The PBTS is ideal for providing the } \\
\text { power from one spot to another remote } \\
\text { spot where you can use power through } \\
\text { hybrid cable." }\end{array}$ & $\begin{array}{l}\text { "The PBTS is ideal for providing the power } \\
\text { from one spot to another remote spot where } \\
\text { you can use power through hybrid cable. It } \\
\text { provides } 400 W \text { DC power to } 1 \mathrm{~km} \text { and } \\
\text { transmits various signals up to } 10 \mathrm{~km} \\
\text { without power." }\end{array}$ \\
\hline K5043 & $\begin{array}{l}\text { "What is next: } \\
\text { - R\&D investment } \\
\text { - Sales network" }\end{array}$ & $\begin{array}{l}\text { "Plans : } \\
2011 \text { Established Development Demo } \\
\text { Model } \\
\text { And Market Test } \\
2012 \text { Established Development Formal } \\
\text { Model } \\
\text { And Global market entry/ Brand awareness } \\
\text { raising } \\
\text { - } 2013 \text { Sales expansion } \\
\text { - } 2014 \text { Item diversification" }\end{array}$ \\
\hline K5077 & $\begin{array}{l}\text { "There is no color-change by ultraviolet } \\
\text { radiation. } \\
\text { And we can give you the advantages } \\
\text { like flame resistance, heat resistance, } \\
\text { durability and good mechanical } \\
\text { maintenance. And, more than } 80 \% \text { from } \\
\text { the existing technologies have been } \\
\text { improved." }\end{array}$ & $\begin{array}{l}\text { "Especially, on automobile glass and } \\
\text { architectural glass, there is no color-change } \\
\text { by ultraviolet radiation. } \\
\text { And our technology provides heat } \\
\text { resistance, durability and improved } \\
\text { mechanical properties of the applied colors } \\
\text { on the glass and the ceramic products. } \\
\text { In additions, according to glass and ceramic } \\
\text { materials, we provide the color which is } \\
\text { able to withstand suitable temperatures and } \\
\text { thermal expansion." }\end{array}$ \\
\hline K5080 & $\begin{array}{l}\text { "What's benefit? } \\
\text { 1. "DIY(Do It Yourself)" type installation } \\
\text { 2. Cheaper price than conventional } \\
\text { security camera } \\
\text { 3. Easy access by PC(Smartphone) in } \\
\text { WiFi zone } \\
\text { 4. Powerful application for Windows } \\
\text { based PC } \\
\text { and Android(IOS) based mobile phone" }\end{array}$ & $\begin{array}{l}\text { "What are the benefit? } \\
\text { 1. Inside Surveillance recording @ SOHO } \\
\text { 2. Easy access by PC (SmartPhone) in } \\
\text { WiFi zone } \\
\text { 3. Real time video data transmission => } \\
\text { Live video on PC or SmartPhone } \\
\text { 4. DIY (Do It Yourself) type } \\
\text { 5. Expansion of surveillance area by } \\
\text { wireless } \\
\text { 6. Replacing the conventional DVR \& } \\
\text { Security Camera system } \\
\text { 7. Significant cost reduction as compared to } \\
\text { conventional security camera" }\end{array}$ \\
\hline K5117 & $\begin{array}{l}\text { "2. Benefit } \\
\text { - Help system administrators manage } \\
\text { their web systems stable } \\
\text { - Provide seamless internet web service } \\
\text { such as e-commerce, internet banking } \\
\text { system, etc" }\end{array}$ & $\begin{array}{l}\text { "2. Benefit } \\
\text { - Easy installation \& Use } \\
\text { - Low maintenance cost } \\
\text { - Right solution for SMB (Small Medium } \\
\text { Business) market" }\end{array}$ \\
\hline K5119 & $\begin{array}{l}\text { "-. Particle size : } 200 \sim 1,000 \mathrm{~nm}(1 \mathrm{~mm}= \\
1,000,000 \mathrm{~nm}) "\end{array}$ & $\begin{array}{l}\text { "-- Our High Cloudy Color by this } \\
\text { technology has an average particle size of } \\
200 \mathrm{~nm} \sim 1000 \mathrm{~nm} \text { for good dispersibility." }\end{array}$ \\
\hline K5141 & Competition's "-Device cost is high" & $\begin{array}{l}\text { Competition's "-Device cost is high } \\
(\$ 20,000) "\end{array}$ \\
\hline K5187 & $\begin{array}{l}\text { Applications include: } \\
\text { " - Successful soldering of different } \\
\text { material (Aluminum-Copper, Nickel- } \\
\text { Copper, Glass-Copper and so on ) } \\
\text { - Customer can develop new products } \\
\text { by overcoming the limit of conventional } \\
\text { soldering method." }\end{array}$ & $\begin{array}{l}\text { Applications include: } \\
\text { " - Successful soldering of different material } \\
\text { (Aluminum-Copper, Nickel-Copper, Glass- } \\
\text { Copper and so on ) } \\
\text { - Customer can develop new products by } \\
\text { overcoming the limit of conventional } \\
\text { soldering method. } \\
\text { - Solders difficult-to wet materials } \\
\text { - Selectively solders complex shapes with } \\
\text { greater process control } \\
\text { - Can cover very large or small areas" }\end{array}$ \\
\hline
\end{tabular}


TABLE V

Incidents of Evidence Modified from Initial to Final Decks, Measured in Numbers of Stanzas Coded

\begin{tabular}{|c|c|c|c|c|c|c|c|}
\hline & \multicolumn{3}{|c|}{ Modified Evidence About... } & \multicolumn{4}{|c|}{ Modified Visuals } \\
\hline Project & Benefits & Business Model & Market & Image & Figure & Table & IP \\
\hline K5006 & 0 & 0 & 0 & 0 & 0 & 1 & 0 \\
\hline K5013 & 0 & 2 & 1 & 3 & 2 & 1 & 2 \\
\hline K5016 & 1 & 1 & 0 & 0 & 0 & 1 & 0 \\
\hline K5043 & 1 & 1 & 3 & 3 & 0 & 3 & 5 \\
\hline K5077 & 0 & 5 & 0 & 6 & 2 & 0 & 0 \\
\hline K5080 & 2 & 1 & 5 & 5 & 0 & 2 & 1 \\
\hline K5084 & 0 & 0 & 1 & 0 & 0 & 0 & 0 \\
\hline K5106 & 0 & 0 & 4 & 2 & 0 & 0 & 0 \\
\hline K5117 & 2 & 3 & 7 & 0 & 1 & 3 & 0 \\
\hline K5119 & 2 & 1 & 1 & 0 & 0 & 0 & 0 \\
\hline K5141 & 1 & 0 & 0 & 0 & 0 & 0 & 1 \\
\hline K5157 & 1 & 0 & 3 & 12 & 0 & 0 & 0 \\
\hline K5187 & 0 & 0 & 0 & 2 & 0 & 0 & 0 \\
\hline K5201 & 2 & 0 & 0 & 0 & 0 & 1 & 0 \\
\hline
\end{tabular}

large family-owned Korean companies (chaebol) such as Samsung and LG (I1.1; cf [36], [67]). Consequently, they say, these entrepreneurs are not used to thinking in terms of external markets, end users, or competitive pricing, and instead make price a percentage of cost (I1.1, I3.1). Failure is strongly stigmatized in Korea, according to GIP personnel, and, consequently, the government tends to broadly subsidize SMEs, lessening the pressure to compete (I1.1). Many innovations tend to focus on import replacement, such as producing domestic versions of products available on the global market; consequently, many innovations offer a value proposition centered on marginal improvements in price, quality, or speed rather than what GIP personnel characterize as a disruptive or a true, broadly recognized value proposition (I1.1, I7.1). Finally, business tends to be oriented around shared, relatively homogenous values and cemented via deep, long-term business relationships rather than price or quality competition (I1.1, I6.1).

Both of these hurdles mean that entrepreneur teams, such as K5080, must undergo training to learn how to compellingly express a value proposition for a specific audience in a specific market, present evidence for that value proposition, and describe an effective team. Teams often find this fundamental shift in perspectives to be very difficult. The GIP Director described it as "[living] in a three-dimensional world and ... trying to sell into a four-dimensional world" (I1.1)-learning to argue in ways that would be effective, yet counterintuitive in their familiar contexts.

Thus, mastering the pitch genre helped successful teams to demonstrate they could argue in ways that synchronized with the market expectations and values of their prospective market partners. Conversely, teams who failed to master the pitch genre were likely to be filtered out.

Expressing the Benefits: Entrepreneurs had to express various benefits, particularly a value proposition, or expression, of the value the customer will receive. They had to move from language describing what a product or technology may mean to a seller/user, to arguments about what the product or technology will do for the business partner. But GIP personnel told us entrepreneur teams have often not thought deeply about the value proposition (I5.1). In fact, these teams are often accustomed to passive approaches to sales, such as taking orders (I1.1, I3.1) and attending trade shows (I2.1), rather than arguing a unique value proposition.

When GIP required them to articulate a value proposition, these entrepreneurs often initially focused on the incremental improvements in price, quality, or speed that had made their products successful domestic import replacements-"me too" improvements that are considered insufficiently compelling value propositions and that often disappear when the products are exported (I1.2, I7.2, I8.2). Sometimes, they had trouble differentiating between features and benefits, that is, between describing product specifications and describing how the product could meet a specific customer need.

Describing the Business Model: GIP personnel also identified the teams' business model and attributes (including ethos claims, such as how long the business has been operational) as a critical part of the pitch. To put together solid pitches, teams 
had to be teachable, receptive, and easy to work with (I1.2, I3.1, I5.1, S2, S12), as well as truthful (I3.1). Teams had to demonstrate they could absorb critiques from the Deep Dive, mentor interactions, and Quicklook reports (S2, S12), and especially that they could address the risks and barriers raised in the Quicklook (S6). They had to engage fully in the process (I7.2), because without that commitment, they were unable to change their pitch sufficiently for the target market.

Providing the Evidence: According to the GIP personnel we interviewed and surveyed, the entrepreneurs in this program were often unprepared to provide specific evidence for their arguments. For instance, one GIP mentor said that early arguments tended to omit evidence and value tests, relying on overbroad claims instead (I3.1). This lack of evidence is particularly important in terms of intellectual property (IP): teams needed to be prepared to offer evidence for patents to even be seriously considered for the program (I1.2, I7.2, I8.2), a move that was sometimes unfamiliar to Korean entrepreneurs, who often relied on trade secrets in their domestic context (I1.2, I5.1).

To summarize, GIP personnel identified various challenges that teams, such as K5080, faced as they tried to remake their pitches for the US market. How well did teams address these challenges? Entrepreneurs had to develop their arguments during their time in the GIP. How much did these arguments develop?

To find out, we focused on two entrepreneurgenerated documents: the initial and final pitch decks. Entrepreneurs revised these documents based on GIP training and documents, but changes ranged from minor rewording (K5043) to complete reworking that involved deleting old slides and adding entirely new ones (K5201). In all, eight entrepreneur teams deleted slides, eleven added slides, and all revised slides (Table III).

Below, we qualitatively examine how entrepreneurs' claims, evidence, and argument complexity changed across these documents. Although we use some tables to show code counts, these tables illustrate general trends and help us to focus our qualitative analysis (cf. Miles and Huberman [45]); they are not intended to support a quantitative analysis.

Revisions in Claims In its Deep Dive presentation, K5080 listed four benefit claims, including a "Cheaper price than conventional security camera." But by the final pitch, it listed seven benefit claims. It also presented these benefit claims differently: the item addressing cost now read "Significant cost reduction as compared to conventional security camera"-a statement that avoided a word with negative connotations ("cheaper") and promised a slightly more specific measure of comparison ("significant"). Similarly, in the final pitch, K5080 clarified its IP status, acknowledged its competition in markets, and clearly specified an underserved market, detailed risks and barriers, and compressed and focused its account of its team status.

Entrepreneurs made many sorts of claims, or disputable statements, including claims about the target market (including the benefits of the product to that target market and its potential for commercialization), for their business model and intellectual property status, and for the status of development (including the time and funds needed to complete development). Many of these claims responded directly to the questions in the application and the sections in the slides template supplied by GIP. (See Table I for these template sections.) It is unclear whether these claims would have been made without this direct guidance from the template, which lays out the expected kinds of claims in the expected order. As Table III suggests, most teams followed the template closely, making minor additions and deletions as they revised. Two diverged sharply from this pattern: K5201's initial deck did not follow the template, but its final deck did; in contrast, K5157's initial deck followed the template, but its final deck did not.

Although most teams followed the overall template, their mix of claims changed from the initial deck to the final slide deck-as K5080's experience illustrates. These changes were specific to the project, since teams' initial slides varied in quality and responded to very different markets. For instance, K5201's initial deck did not follow the supplied template, instead focusing heavily on market claims to the exclusion of other claims; the final deck did follow the template, leading it to address business model and market claims. K5043's deck changed only slightly in revision; K5157 added eight slides and deleted 15, and its mix of claims also changed.

The quality of the changes became clearer as we examined the decks themselves. The claims frequently changed from the initial to final decks, often becoming more specific (Table IV). For all 14 entrepreneur teams, claims from the initial deck are reused in the final deck, but there is a change in wording or details to provide more evidence-based and benefit-oriented language. For 
instance, K5201's initial deck lists specifications, such as power consumption; their final deck lists specifications more appropriate for server operators, such as software functions and Ethernet ports. Similarly, K5016's initial deck briefly describes transmitting and compressing a signal; their final deck specifies the transmission and compression methods. For all projects, entrepreneurs made more specific claims after going through training and responding to the GIP documents.

Although revision often involved increasing the number of claims, it also involved refining claims and sometimes removing them, actively responding to the GIP documents and training to form a more focused, coherent argument. For instance, K5141's benefit claims dropped from 33 stanzas in the initial deck to 22 in the final deck. The initial deck featured a 128-word discussion of the expected effects of new technology; the final deck replaced this discussion with a figure containing six words. At the same time, K5141 added one business model claim and two market claims to better position the pitch for the US market.

This refining of claims, in fact, often demonstrated a shift from claims that appealed to Korean partners to those that appealed to partners in US markets. For instance, K5077's claims about its business model dropped sharply from 21 stanzas in the initial deck to 11 in the final deck. Part of that drop had to do with the last slide in the initial deck, which envisioned how an award K5077 had already won ("The Exporter-award over 3 million dollar") would be replaced by an award it planned to win ("The Exporter-award over 5 million dollar"). Although these awards may have been significant for the entrepreneur and for the subsidies that the entrepreneur expected to receive from the Korean government, they had no significance for global partners. In the final deck, they were replaced by slides that responded to the concerns of global partners: slides describing market interest, competition, risks and barriers, and team status.

Claims, then, demonstrably developed between the initial and final decks. Claims that fit the target markets' expectations, such as K5187's list of applications, were retained, expanded, and added; claims that did not, such as K5077's stated ambition to win an award, were removed. Individually, the final decks moved (in big and small ways) toward portfolios of claims oriented to their target markets.
These claims were backed by evidence, and we found that teams generally adjusted their use of evidence from the initial to final pitches.

Revisions of Evidence In the K5080's initial deck, the team produced important evidence of market interest: "Total 10 Customers order Sample, (Japan 8, S. Asia 2)." But this evidence is insufficient, and the Quicklook raises a note of caution: "Other than a few sample sales, the company does not have any sales." Can K5080 substantiate its claim that the market is interested? To do so, K5080 restates the evidence, removing less convincing aspects (the specific countries and individual number breakdown) and adding more convincing ones: the fact that five customers bought the product on a marketing promotion, the results from additional product demonstrations, and an indirect quote from the Quicklook itself.

All 14 entrepreneurs' initial and final decks used evidence - statements of fact supporting their claims. This evidence included direct and indirect quotes, market figures, sales numbers, patent numbers, graphs, and even clip art and photos. As K5080's experience implies, many pieces of evidence can be traced back to the Quicklooks, which partly functioned as data sources for the final decks. (That is, in using this evidence, the entrepreneurs were responding to the representation of the market.) Like $\mathrm{K} 5080$, all 14 of the final decks also modified their evidence as they developed their final pitches, some radically. But that evidence varied considerably, often in support of their changing claims.

Six entrepreneur teams, including K5080, showed net gains in their overall quantity of evidence. These net gains sometimes signaled refinements in argument. For instance, K5084, which described a new uninterrupted power supply, added a slide to their final deck to tell a story illustrating the market's need for the product: an 11-minute power loss that cost a factory " 6 million." Other instances involved adding evidence, such as citations and quotes. K5043, for example, replaced abstract sources of market interest with quotes mined directly from the Quicklook report, while K5187 added multiple journal citations.

Evidence was removed and added. For instance, K5157 had, by far, the highest number of incidents of evidence in its initial deck, but removed several of these in the final deck-largely because the initial deck focused on their large number of Korean patents, which were irrelevant in the global market. Similarly, K5077 removed evidence, such 
as a superfluous figure, showing its relationship to manufacturers as well as overspecified, text-heavy market benefits and replaced them with more concise benefit listings. As these two examples suggest, removing evidence involved determining which evidence was necessary to support the proper claims for the specific audience.

Between adding and removing, all teams changed their mix of qualitative and quantitative evidence over time, with three adding visuals, four adding citations, three adding quotes, and six adding examples. Even though two teams did not change the overall number of evidence incidents, the mix of evidence incidents changed for every team. And as Table $\mathrm{V}$ illustrates, teams modified existing evidence from initial to final decks.

Revising Evidence About Markets: As Table V shows, eight of the teams modified evidence supporting their market claims, primarily in dialogue with the Quicklook reports. For instance, K5119 turned a narrative description of the market from the initial deck into a table with quantitative data in its pitch slides. (Since the evidence was turned into a table format, this incident is not counted as a modified table, but rather as a new table.) Similarly, K5117 added a new slide to its final deck with evidence demonstrating that the small and medium business market uses PHP-driven websites.

Revising Evidence About Benefits: As mentioned earlier, eight modified evidence supporting their benefit claims. For instance, in K5117's final pitch, they significantly revise a table, name different competitors, and provide different metrics for comparing them.

Revising Evidence About the Business Model: Seven of the teams modified evidence used to support claims about their business model, including more specifics about the team (K5016) and its development cycle (K5013). Four teams modified evidence claims about their intellectual property. For instance, K5080's pitch adds the individual countries where they had filed for patent protection.

Not surprisingly, all 14 pitches used visual evidence in the form of images, figures, and tables. Of these, from the initial deck to the final deck, 7 modified images, 3 modified figures, and 7 modified tables.

In terms of evidence, then, entrepreneurs clearly developed their arguments from their initial to final decks, although these developments were inconsistent across projects. These modifications had much to do with the strengths and weaknesses of their initial pitches as well as the idiosyncrasies of the specific markets they sought to enter. Importantly, the entrepreneurs often modified their evidence in direct response to the Quicklooks and training, developing their portfolio of evidence for their claims.

Revisions of Argument Complexity As they began presentation training, K5080 received the GIP's Quicklook for their project, and it was not entirely positive. In fact, the Quicklook recommended that K5080 proceed "cautiously" in commercializing for the US market because K5080's product faced stiff competition in the market segment that the Quicklook had identified. Competitors existed, others were soon to enter the market, and the product's features did not match this market well. In short, the Quicklook did not see a strong value proposition for K5080's product.

K5080 disagreed, and pinned the problems on a misunderstanding of the intended market and capabilities. In the final pitch, K5080 included two "Q\&A" slides rebutting concerns in the Quicklook, identifying the target market more precisely, disputing concerns about its technology, and laying out a strategy to address any remaining concerns. In the process, K5080 visibly changed its claims and the evidence that supported them-making its argument more complex by using rebuttals and qualifiers to more precisely locate its claim. K5080's dialogue did not just involve adopting claims and evidence from GIP documents: it also involved rebutting or qualifying claims and evidence when appropriate.

Argument complexity is harder than making specified types of claims and offering specified types of evidence. It involves responding to the Quicklook authors' comments and anticipating the objections of market partners. The dialogue involves more than being informed by the market feedback, it also involves clarifying and qualifying one's claims and rebutting the claims of the Quicklook. In some cases, such as K5080's, that meant violating the formal constraints of the pitch genre to better address its purposes (cf. [63]).

In our coding scheme, we define a rebuttal as a mitigation: an argument that concedes and minimizes the impact of negative claims against the product or its disadvantages. A qualifier is a hedge or limitation in claim. Some rebuttals and qualifiers responded to counters in the GIP documents: counterclaims against either the product or a market condition facing the product.

As noted earlier, K5080 was not alone. Five entrepreneur teams (K5013, K5080, K5084, K5141, 
TABLE VI

Slides AdDed to Final Decks to Rebut Quicklook Counters

\begin{tabular}{l|l|l|l}
\hline Project & Slide & Description & $\begin{array}{l}\text { Rebuttal or } \\
\text { Counter }\end{array}$ \\
\hline K5013 & $\begin{array}{l}\text { "Potential Challenges } \\
\text { (Quicklook report by } \\
\text { UT)" }\end{array}$ & List of Quicklook counters & Counter \\
\hline K5080 & $\begin{array}{l}\text { "Appendix: Q\&A 1" } \\
\text { "Appendix: Q\&A 2" }\end{array}$ & $\begin{array}{l}\text { List of Quicklook counters and team's } \\
\text { rebuttals }\end{array}$ & $\begin{array}{l}\text { Rebuttal, } \\
\text { counter }\end{array}$ \\
\hline K5084 & "SWOT Anaysis" & $\begin{array}{l}\text { SWOT analysis indirectly including } \\
\text { counters from Quicklook and team's } \\
\text { rebuttals }\end{array}$ & $\begin{array}{l}\text { Rebuttal, } \\
\text { counter }\end{array}$ \\
\hline K5141 & "7. Competition" & $\begin{array}{l}\text { List of Quicklook counters and team's } \\
\text { rebuttals }\end{array}$ & $\begin{array}{l}\text { Rebuttal, } \\
\text { counter }\end{array}$ \\
\hline K5157 & "Go-To-Market & $\begin{array}{l}\text { SWOT analysis indirectly including } \\
\text { counters from Quicklook and team's } \\
\text { rebuttals }\end{array}$ & $\begin{array}{l}\text { Rebuttal, } \\
\text { counter }\end{array}$ \\
\hline
\end{tabular}

K5157) created entirely new slides to directly counter or indirectly rebut concerns raised in their Quicklook - they actually modified the GIP template. (See Table VI.) These modifications suggest that the teams learned the genre well enough to adapt it to their advantage; the GIP presentation trainer told us that she sometimes encourages this sort of adaptation.

Not all changes were so dramatic: rather than adding new slides, many worked rebuttals and qualifiers into their existing slides. All 14 projects included rebuttals and qualifiers responding to concerns raised in the GIP's documents (Deep Dive Comments and Quicklook reports), demonstrating that the entrepreneurs modified their arguments to address presented concerns. For instance, K5016's Quicklook raised an intellectual property concern: "They have not yet filed for PCT [Patent Cooperation Treaty] coverage to secure intellectual property protection, but plan to file in the near future." K5141 rebutted that concern in the final slide deck: "We are planning to file for PCT coverage to secure IP by end of this month for the hardware configuration and software design." This result is very positive for the GIP, since it means that entrepreneurs have learned to actively respond to market concerns through the pitch.

Again, the raw code counts give us an idea of the shifts, but do not tell the whole story. For instance, K5084 created a new slide intended solely to rebut Quicklook concerns, but did not increase their net number of rebuttals and qualifiers. Similarly, K5141 had a net addition of just one rebuttal, but its deck also added a slide to respond to the Quicklook.

Do entrepreneurs develop their pitch decks as a result of going through the GIP, demonstrating the ability to engage in dialogue with market stakeholders? The analysis suggests that many do, in terms of claims, evidence, and complexity. As we have seen, all but one project (K5106) increased the number of stanzas coded as claims, evidence, or complexity (rebuttals or qualifiers) from initial to final decks; all projects modified evidence between the initial and final decks. Five of the entrepreneurial teams even took the unusual step of adding a slide just to rebut counterarguments in the Quicklook.

Yet, as the above suggests, these changes are not uniform. That is to be expected, since these entrepreneurs are starting in very different places, pitching very different innovations to different markets, and facing very different kinds of feedback from the GIP documents they received. In addition, some teams were already more prepared than others. Nevertheless, teams all changed their arguments in detectable ways as they responded to the GIP documents and training.

\section{CONCLUSIONS, LIMITATIONS, AND SUgGESTIONS FOR FUTURE RESEARCH}

Throughout this study, we have analyzed how entrepreneurs developed their pitch arguments within a dialogue that takes place across a document cycle. We have noted changes in their claims, evidence, and argument complexity, and changes that demonstrate how the pitch decks are responsive to other documents. In this final section, we discuss our conclusions, the study's limitations, and suggestions for future research.

Conclusions Although many studies have examined document cycles and revisions in professional communication, and although some studies have examined business pitches, to our knowledge, this is the first study to examine pitch revisions. 
Through this study, we developed a preliminary understanding of how entrepreneurs address their dialogue with the market by adjusting their pitches, specifically in terms of the claims and evidence they choose to use and the complexity of their pitches.

In fact, this approach allowed us to trace revisions related to other documents in the cycle. The results suggest that all entrepreneurs adjusted their arguments based on the feedback from the GIP documents. More important, some entrepreneurs continued the dialogue, so to speak, by rebutting some concerns in these documents and even adding slides that do not fit in the pitch genre they learned-a more complex response to the dialogue, and one that GIP personnel tell us suggests a more sophisticated understanding of entrepreneurship.

Limitations At the same time, the study has several limitations.

First, as exploratory qualitative research, the study cannot be generalized to other entrepreneurs or programs.

Second, the case itself has limitations. Since we focused on one entrepreneurial program, we cannot confidently separate contextual factors, such as the cultural divide between entrepreneurs and their target markets; the specific sectors in which the entrepreneurs operated; or the differences in potential stakeholders, such as customers, distributors, and licensees.

Third, given its exploratory nature, the scope of the research was limited. We examined a subset of documents from a single year of the program, we did not interview the pitchers, we did not observe the training or the competition pitches, and we did not examine entrepreneurs' documents beyond the program, documents aimed at specific "catchers."

Finally, the focus of the research was limited to revising the pitch deck. As the existing literature on pitches makes clear, the pitch deck is important, but so are other factors, such as delivery and charisma.

Suggestions for Future Research Nevertheless, as perhaps the first study examining the revision of pitch decks, this study has implications for entrepreneurship programs, for studies of pitches, and for studies of revision across document cycles.

First, this study indicates points at which entrepreneurship programs such as the GIP could identify tacit, context-bound practices and criteria, a first step toward developing more explicit, systematic approaches to training. As discussed earlier, these programs draw on experts from many different areas and guide entrepreneurs, who target many different sectors and markets. Consequently, these programs often rely heavily on the expertise and judgment of highly situated individuals. Our results, we believe, could provide some explicit guidance for revisions that could apply across these very different contexts.

Second, this study provides a starting point for future studies of pitches. These future studies, we believe, should address the limitations of this first, exploratory study. Specifically, they should further contextualize the pitch development process by coordinating similar revision analyses with entrepreneur interviews, observations of pitch delivery, and observations of catcher deliberations. They should also examine revisions in terms of how and when entrepreneurs reuse claims and evidence from other documents. Finally, they should examine the pitch process in other entrepreneur programs as well as pitching outside such programs. In subsequent studies, we plan to examine this dialogic process more closely; we will apply a similar analysis to GIP documents in order to better understand how innovators and GIP personnel interact as they do when developing these arguments.

Third, beyond pitches, we believe this approach has promise for understanding general revision processes across document cycles. By coding for claims and evidence, we could identify shifts in argument structure between revisions; identifying such shifts could be useful for other cases in which people revise persuasive documents in response to feedback. These cases include proposals and technical reports. 


\section{APPENDIX A}

\section{PhASE 1 INTERVIEW QUeSTIONS}

Describe your education and professional background.

- What degree(s) have you earned and when? What is your work experience?

- How have you applied these in your role as mentor? What qualities make a mentor effective/ineffective?

Describe the teams that you mentor.

- What backgrounds do they typically have?

- Stage of product development?

- How large are the teams you mentor directly?

- What experience do they usually have when they get to you? What deficits, if any, do teams have when they come to you?

Describe a typical cycle of mentorship.

- How is this team assigned to you?

- What do you do to get to know this team and their projects?

- What do you teach them during the mentorship?

- What are the main phases of mentorship? How long does each last?

- When do people "graduate" from the mentorship? What constitutes "graduation"?

- Do teams ever fail to graduate, and why is this?

What sorts of aids do you use during the mentoring cycle?

- slide decks

- scripted or semi-scripted presentations

- Can you provide examples of documents?

What sorts of texts and communication are involved in this mentorship cycle, and what do you teach them about these? For instance,
- What documents (texts, slide decks, etc.) do you teach them to produce and

- improve?

- What coordination skills (project management, internal coordination) do you

- teach them or expect them to use?

- What communication skills (e.g., handling themselves during client meetings) do

- you teach them or expect them to use?

Next Steps

- How do you select teams that move from mentorship to business development?

- What criteria are used?

- Include relevant criteria for the teams, product, market opportunity/size, and "fit

- with GCG capabilities?

- How are business leads found?

- What mentorship is practiced during the business development phase?

- How does this differ from that provided before the competition?

- To what extent, and in what circumstances, do you keep in contact with teams after mentoring is complete? Do you help them "network", provide informal mentoring, review documents, etc.?

Performance Metrics

- What milestones are the teams that you mentor expected to reach? Competition

- Phase? Business Development Phase?

- What methods does your team use to track these team cooperation and

- performance?

- Do you track teams after graduating the program? For how long?

\section{APPENDIX B}

\section{PhASE 2 INTERVIEW QUeSTIONS}

- What do you look for in a successful application? That is, what criteria does a successful application need to meet?

- What are some "red flags" or indicators that an application is not ready?
- What role does your experience in previous years of deliberations play?

- To what extent is your deliberation affected by the contacts you currently have across industries?

\section{APPENDIX C}

\section{INTERNAL SURVEY}

(1) What value does the application provide to the GCG?
(2) What value does the application provide to the innovators?

(3) How is this value communicated to the innovators? 
(4) What value does the deep dive PowerPoint provide to the GCG?

(5) What value does the deep dive PowerPoint provide to the innovators?

(6) How is this value communicated to the innovators?

(7) What value does the Quicklook ${ }^{\circledR}$ provide to the GCG?

(8) What value does the Quicklook ${ }^{\circledR}$ provide to the innovators?

(9) How is this value communicated to the innovators?
(10) What value does the final PowerPoint provide to the GCG?

(11) What value does the final PowerPoint provide to the innovators?

(12) How is this value communicated to the innovators?

(13) In a sentence or two, please describe the overall value of the Gyeoneggi-UT Innovation Program. 
This article has been accepted for inclusion in a future issue of this journal. Content is final as presented, with the exception of pagination.

\section{APPENDIX D}

\section{SAMPLE CODES}

\begin{tabular}{|c|c|c|}
\hline Code & Description & Example \\
\hline claim & $\begin{array}{l}\text { A disputable statement; a } \\
\text { statement that readers need } \\
\text { evidence in order to consider }\end{array}$ & \\
\hline claim_problem & $\begin{array}{l}\text { A claim that defines the problem } \\
\text { and/or solution }\end{array}$ & $\begin{array}{l}\text { "Except aluminum pallet, there are } \\
\text { many problems with pallets." }\end{array}$ \\
\hline claim_benefit & $\begin{array}{l}\text { A claim that refers to the product. } \\
\text { This could be a benefit the } \\
\text { product provides, but it is not } \\
\text { limted to this defintion. }\end{array}$ & $\begin{array}{l}\text { "[Product] allows having a proactive } \\
\text { approach to ensure application } \\
\text { availability and enhanced } \\
\text { application performance." }\end{array}$ \\
\hline claim_marketuse & $\begin{array}{l}\text { A claim that defines the market } \\
\text { use of the solution }\end{array}$ & $\begin{array}{l}\text { "Cost reduction: extremely light but } \\
\text { enough strong aluminum pallets } \\
\text { can reduce air-logistics cost." }\end{array}$ \\
\hline evidence & $\begin{array}{l}\text { A statement of fact that supports } \\
\text { a claim }\end{array}$ & \\
\hline evidence_table & $\begin{array}{l}\text { Evidence presented in a table } \\
\text { format. }\end{array}$ & \\
\hline evidence_figure & $\begin{array}{l}\text { Evidence presented in a graph, } \\
\text { chart, or figure other than a } \\
\text { photo or line drawing. }\end{array}$ & \\
\hline evidence_image & $\begin{array}{l}\text { Evidence presented in a photo or } \\
\text { line drawing. }\end{array}$ & \\
\hline evidence_quote & Evidence presented in a quote. & $\begin{array}{l}\text { "Mr. Rhu, CTO of Prudential } \\
\text { explained, 'through [Product]'s } \\
\text { intuitive dashboard, colorful } \\
\text { graphics, and customized screens } \\
\text { you can see the entire WAS system } \\
\text { from a single monitor, and because } \\
\text { it allows you to respond to } \\
\text { performance problems and error } \\
\text { conditions in real-time, you can't } \\
\text { help but like it. This is why we } \\
\text { decided to leave [Competitor] and } \\
\text { go with [Product] again."” }\end{array}$ \\
\hline evidence_quantitative & Evidence presented numerically. & "Total cost/pallet: $\$ 48 "$ \\
\hline evidence_qualitative & $\begin{array}{l}\text { Evidence presented } \\
\text { nonnumerically. }\end{array}$ & "Strength: never break" \\
\hline evidence_comparative & $\begin{array}{l}\text { Evidence that is an explicit } \\
\text { comparison. }\end{array}$ & "Weight: $1 / 3$ or more lighter" \\
\hline qualifier & A hedge; a limitation in claim. & $\begin{array}{l}\text { "1. Risks and Barriers- Technical } \\
\text { challenges : End-user monitoring, } \\
\text { SaaS platform-based servic" }\end{array}$ \\
\hline rebuttal & $\begin{array}{l}\text { A mitigation; an argument that } \\
\text { concedes and minimizes the } \\
\text { impact of negative claims against } \\
\text { the product/ disadvantages. }\end{array}$ & $\begin{array}{l}\text { "2. Plan to overcome these } \\
\text { challenges- [Product] } 5 \text { include all } \\
\text { those feature and we plan to } \\
\text { release [Product] } 5 \text { in this year." }\end{array}$ \\
\hline claim_ip_copyright & Claim to copyright protections & $\begin{array}{l}\text { Answers to Question \#14 from } \\
\text { App: What IP protections does } \\
\text { the technology currently have? }\end{array}$ \\
\hline evidence_ip_patent & $\begin{array}{l}\text { Evidence in the form of patent } \\
\text { numbers }\end{array}$ & Patent Number : [\#] \\
\hline claim_devstatus & $\begin{array}{l}\text { A claim about the development } \\
\text { status of the product }\end{array}$ & $\begin{array}{l}\text { Answer to Question \#18 from } \\
\text { App: What is the current status } \\
\text { of this innovation? }\end{array}$ \\
\hline claim_devtime & $\begin{array}{l}\text { A claim about the time needed } \\
\text { to develop the product for } \\
\text { market }\end{array}$ & $\begin{array}{l}\text { Answer to Question \#19 from } \\
\text { App: How many calendar } \\
\text { months do you estimate will be } \\
\text { required before this innovation } \\
\text { is completely developed and } \\
\text { ready for the market? }\end{array}$ \\
\hline claim_devcost & $\begin{array}{l}\text { A claim about the cost to } \\
\text { develop the product for market }\end{array}$ & $\begin{array}{l}\text { Answer to Question } 20 \text { from } \\
\text { App: What is the total cost } \\
\text { (including manpower, } \\
\text { equipment and all other } \\
\text { resources) required to } \\
\text { complete market-ready } \\
\text { development of this } \\
\text { innovation? }\end{array}$ \\
\hline claim_3rdparty & $\begin{array}{l}\text { A claim about official 3rd party } \\
\text { evaluation. }\end{array}$ & $\begin{array}{l}\text { Answer to Question } 24 \text { from } \\
\text { App: What 3rd Party validation } \\
\text { has innovation undergone? }\end{array}$ \\
\hline claim_busmodel & $\begin{array}{l}\text { A claim about the business } \\
\text { model of the company. This } \\
\text { could be a sugestion of how a } \\
\text { company should be or is run, if } \\
\text { resources should be allocated } \\
\text { to marketing, or the like. }\end{array}$ & \\
\hline evidence_cited & $\begin{array}{l}\text { Evidence that has a formal } \\
\text { citation or indicator of source. }\end{array}$ & $\begin{array}{l}\text { Multi-PC will replace } 40 \% \text { of } \\
\text { the desktop market (Gartner. } \\
2011 \text { ) }\end{array}$ \\
\hline claim_market_US & A claim about the US market & $\begin{array}{l}\text { [Product] has potential in the } \\
\text { US }\end{array}$ \\
\hline claim_com_int & $\begin{array}{l}\text { A claim about the } \\
\text { commercialization of the } \\
\text { product globally (outside S. } \\
\text { Korea). }\end{array}$ & $\begin{array}{l}\text { Current sales and marketing } \\
\text { activity for overseas market }\end{array}$ \\
\hline
\end{tabular}




\section{REFERENCES}

[1] M. M. Bakhtin, The Dialogic Imagination: Four Essays. Austin, TX, USA: University of Texas Press, 1981.

[2] M. M. Bakhtin, Problems of Dostoevsky's Poetics. Minneapolis, MN, USA: University of Minnesota Press, 1984.

[3] M. M. Bakhtin, Speech Genres and Other Late Essays. Austin, TX, USA: University of Texas Press, 1986.

[4] D. Ballantyne and R. J. Varey, "Creating value-in-use through marketing interaction: The exchange logic of relating, communicating and knowing," Mark. Theory, vol. 6, no. 3, pp. 335-348, Sep. 2006.

[5] D. Ballantyne, P. Frow, R. J. Varey, and A. Payne, "Value propositions as communication practice: Taking a wider view," Ind. Mark. Manage., vol. 40, no. 2, pp. 202-210, Feb. 2011.

[6] M. Bannerjee, M. Capozzoli, L. McSweeney, and D. Sinha, "Beyond Kappa: A review of interrater agreement measures," Can. J. Stat., vol. 27, no. 1, pp. 3-23, 1999.

[7] C. E. Beck and K. A. Wegner, "Enthusiasm in technical proposals: Verifying a method of lexical analysis," IEEE Trans. Prof. Commun., vol. 33, no. 3, pp. 118-123, Sep. 1990.

[8] T. Bjerregaard and C. Jonasson, "Managing unstable institutional contradictions: The work of becoming," Organ. Stud., Jun. 2014.

[9] G. J. Broadhead and R. Freed, The Variables of Composition: Process and Product in a Business Setting. Carbondale, IL, USA: Southern Illinois University Press, 1986.

[10] X.-P. Chen, X. Yao, and S. Kotha, "Entrepreneur passion and preparedness in business plan presentations: A persuasion analysis of venture capitalists' funding decisions," Acad. Manage. J., vol. 52, no. 1, pp. 199-214, Feb. 2009.

[11] C. Clark, “The impact of entrepreneurs' oral 'pitch' presentation skills on business angels' initial screening investment decisions," Ventur. Cap., vol. 10, no. 3, pp. 257-279, Jul. 2008.

[12] G. Convertino, V. Bellotti, N. Ikeya, O. Brdiczka, A. Hoshino, M. Sakaguchi, Y. Motohashi, and H. Sakagaminec, "Opportunities for proactive support of reuse and organizational learning in ad hoc collaborative work activity?: A field study of proposal writing," in Proc. Int. Conf. Collab. Technol. Syst., 2011, pp. 143-150.

[13] J. Corbin and A. C. Strauss, Basics of Qualitative Research: Techniques and Procedures for Developing Grounded Theory, 3rd ed. Thousand Oaks, CA, USA: Sage, 2008, p. 400.

[14] B. Cornwell, “Quicklook' commercialization assessments,” Innov. Manag. Policy Pract., vol. 1, no. 1, pp. 7-9, 1998.

[15] B. Couture and J. Rymer, "Discourse interaction between writer and supervisor: A primary collaboration in workplace writing," in Collaborative Writing in Industry: Investigations in Theory and Practice, M. M. Lay and W. M. Karis, Eds. Amityville, NY, USA: Baywood, 1991, pp. 87-108.

[16] A. J. Devitt, J. G. Bazerman and C. Paradis, Eds., "Intertextuality in tax accounting: Generic, referential, and functional," in Textual Dynamics of the Professions: Historical and Contemporary Studies of Writing in Professional Communities. Madison, WI, USA: University of Wisconsin Press, 1991, pp. $336-357$.

[17] H. Ding, "The use of cognitive and social apprenticeship to teach a disciplinary genre: Initiation of graduate students into NIH grant writing," Writ. Commun., vol. 25, no. 1, pp. 3-52, Jan. 2008.

[18] P. F. Drucker, Innovation and Entrepreneurship. New York, USA: HarperBusiness, 1993.

[19] L. Faigley, "Competing theories of process: A critique and a proposal," Coll. English, vol. 48, no. 6, p. 527, Oct., 1986.

[20] L. Flower and J. R. Hayes, "A cognitive process theory of writing," Coll. Compos. Commun., vol. 32, no. 4, pp. 365-387, 1981.

[21] L. Flower, J. R. Hayes, and H. Swarts, P. V. Anderson, R. J. Brockmann, and C. R. Miller, Eds., "Revising functional documents: The scenario principle," in New Essays in Technical and Scientific Communication: Research, Theory, Practice. Farmingdale, NY, USA: Baywood, 1983, pp. 41-58.

[22] S. Fraiberg, "Reassembling technical communication: A framework for studying multilingual and multimodal practices in global contexts," Tech. Commun. Quart., vol. 22, no. 1, pp. 10-27, Jan. 2013.

[23] J. B. Freeman, Dialectics and the Macrostructure of Arguments: A Theory of Argument Structure. New York, USA: Walter de Gruyter, 1991, vol. 10.

[24] E. Friess, "Politeness, time constraints, and collaboration in decision-making meetings: A case study," Tech. Commun. Quart., vol. 20, no. 2, pp. 114-138, Mar. 2011.

[25] E. Friess, "Designing from data: Rhetorical appeals in support of design decisions," J. Bus. Tech. Commun., vol. 24, no. 4, pp. 403-444, Aug. 2010.

[26] P. Frow and A. Payne, "A stakeholder perspective of the value proposition concept," Eur. J. Market., vol. 45, no. $1 / 2$, pp. 223-240, 2011.

[27] C. S. Galbraith, B. C. McKinney, A. F. DeNoble, and S. B. Ehrlich, "The impact of presentation form, entrepreneurial passion, and perceived preparedness on obtaining grant funding," J. Bus. Tech. Commun., vol. 28, no. 2, pp. 222-248, Dec. 2014.

[28] D. V. Gibson and P. Conceiçao, , L. V. Shavinina, Ed., "Incubating and networking technology commercialization centers among emerging, developing, and mature technopoleis worldwide," in International Handbook on Innovation. Oxford, UK: Elsevier, 2003, pp. 739-749.

[29] T. Govier, Problems in Argument Analysis and Evaluation. New York, USA: Walter de Gruyter, 1987, vol. 5.

[30] A. Greenman, "Entrepreneurial activities and occupational boundary work during venture creation and development in the cultural industries," Int. Small Bus. J., vol. 30, no. 2, pp. 115-137, Dec. 2011.

[31] C. Haas and S. Witte, "Writing as embodied practice: The case of engineering standards," J. Bus. Tech. Commun., vol. 15, no. 4, pp. 413-457, 2001. 
[32] W. Hart-Davidson, M. Zachry, and C. Spinuzzi, "Activity streams: Building context to coordinate writing activity in collaborative teams," in Proc. 30th ACM Int. Conf. Design Commun., 2012, pp. $279-287$.

[33] E.-M. Jakobs and C. Spinuzzi, E.-M. Jakobs and D. Perrin, Eds., "Professional domains: Writing as creation of economic value," in Handbook of Writing and Text Production. Berlin, NJ, USA: De Gruyter, 2014.

[34] J. Jones, "Patterns of revision in online writing: A study of Wikipedia's featured articles," Writ. Commun., vol. 25, pp. 262-289, 2008.

[35] R. Kent-Drury, "The nature of leadership in cross-functional proposal-writing groups," Tech. Commun., no. 2000, pp. 90-98, 2000.

[36] J. Kim, Crisis \& Change. Seoul, Korea: Ewha Womans University Press, 2005.

[37] S. Kleimann, , R. Spilka, Ed., "The reciprocal relationship of workplace culture and review," in Writing in the Workplace: New Research Perspectives. Carbondale, IL, USA: Southern Illinois University Press, 1993, pp. 71-83.

[38] C. Kowalkowski, "Dynamics of value propositions: Insights from service-dominant logic," Eur. J. Market., vol. 45, no. 1/2, pp. 277-294, 2011.

[39] C. Kowalkowski, O. P. Ridell, J. G. Röndell, and D. Sörhammar, "The co-creative practice of forming a value proposition," J. Mark. Manage., vol. 28, no. 13-14, pp. 1553-1570, Dec., 2012.

[40] P. Kristensson, J. Matthing, and N. Johansson, "Key strategies for the successful involvement of customers in the co-creation of new technology-based services," Int. J. Serv. Ind. Manage., vol. 19, no. 4, pp. 474-491, 2008.

[41] C. Locke, R. Levine, D. Searls, and D. Weinberger, The Cluetrain Manifesto: The End of Business as Usual. New York, USA: Perseus Books Group, 2001.

[42] R. F. Lusch and F. E. Webster, "A stakeholder-unifying, cocreation philosophy for marketing," J. Macromarket., vol. 31, no. 2, pp. 129-134, Mar. 2011.

[43] J. E. McCarthy, J. T. Grabill, W. Hart-Davidson, and M. McLeod, "Content management in the workplace: Community, context, and a new way to organize writing," J. Bus. Tech. Commun., vol. 25, no. 4, pp. 367-395, Jun. 2011.

[44] C. M. McIsaac and M. A. Aschauer, "Proposal writing at Atherton Jordan Inc: An ethnographic study," Manage. Commun. Quart., vol. 3, no. 4, pp. 527-560, 1990.

[45] M. B. Miles and A. M. Huberman, Qualitative Data Analysis: An Expanded Sourcebook. Thousand Oaks, CA, USA: Sage, 1994.

[46] C. R. Miller, "Genre as social action," Q. J. Speech, vol. 70, no. 2, pp. 151-167, 1984.

[47] J. T. Morgan and M. Zachry, "Negotiating with angry mastodons," in Proc.16th ACM Int. Conf. Supporting Group Work, 2010, pp. 165-168.

[48] E. O’Connor, "Storied business: Typology, intertextuality, and traffic in entrepreneurial narrative," J. Bus. Commun., vol. 39, no. 1, pp. 36-54, Jan. 2002.

[49] L. Odell and D. Goswami, Writing in Nonacademic Settings. New York, USA: Guilford Press, 1985.

[50] J. Paradis, D. Dobrin, and R. Miller, L. Odell and D. Goswami, Eds., "Writing at Exxon ITD: Notes on the writing environment of an R\&D organization," in Writing in Nonacademic Settings. New York, USA: Guildford Press, 1985, pp. 281-308.

[51] A. Paré, "Discourse regulations and the production of knowledge," in Writing in the Workplace: New Research Perspectives, R. Spilka, Ed. Carbondale, IL, USA: Southern Illinois University Press, 1993, pp. 111-123.

[52] J.-B. Park, T.-K. Ryu, and D. V. Gibson, "Facilitating public-to-private technology transfer through consortia: Initial evidence from Korea," J. Technol. Transfer, vol. 35, no. 2, pp. 237-252, May 2009.

[53] J. M. Pollack, M. W. Rutherford, and B. G. Nagy, "Preparedness and cognitive legitimacy as antecedents of new venture funding in televised business pitches," Entrep. Theory Pract., vol. 36, no. 5, pp. 915-939, Sep. 2012.

[54] M. Rencher, Crossing the Valley of Death: A Multi-Sited, Multi-Level Ethnographic Study of Growth Startups and Entrepreneurial Communities in Post-Industrial Detroit. Detroit, MI, USA: Wayne State University, 2012.

[55] T. Rintamäki, H. Kuusela, and L. Mitronen, "Identifying competitive customer value propositions in retailing," Manag. Serv. Qual., vol. 17, no. 6, pp. 621-634, 2007.

[56] D. R. Russell, "Rethinking genre in school and society: An activity theory analysis," Writ. Commun., vol. 14, no. 4, pp. 504-554, 1997.

[57] J. Saldana, The Coding Manual for Qualitative Researchers. Thousand Oaks, CA, USA: Sage, 2013.

[58] H. E. Sales, "The information structure of engineering proposals: Suggesting a taxonomy of information components for competitive proposals and a potential metric for information content," presented at the IEEE Int. Profess. Commun. Conf., Montreal, QC, Canada, 2008.

[59] B. Sauer, The Rhetoric of Risk: Technical Documentation in Hazardous Environments. Mahwah, NJ, USA: Erlbaum, 2003.

[60] M. L. Schuster and A. D. Propen, Victim Advocacy in the Courtroom: Persuasive Practices in Domestic Violence and Child Protection Cases. Boston, MA, USA: Northeastern Univ. Press, 2011.

[61] M. Simosi, "Using Toulmin's framework for the analysis of everyday argumentation: Some methodological considerations," Argumentation, vol. 17, no. 2, pp. 185-202, 2003.

[62] P. Skålén, J. Gummerus, C. Koskull, and P. R. Magnusson, "Exploring value propositions and service innovation: A service-dominant logic study," J. Acad. Mark. Sci., Feb. 2014.

[63] G. Smart, "A central bank's combined use of written/oral genres and technology to orchestrate Its 'communications strategy' in the arena of public policy," Writing Selves/Writing Societies: Research From Activity Perspectives, pp. 9-61, The WAC Clearinghouse and Mind, Culture, and Activity, Ft. Collins, CO, USA, 2003. 
[64] M. M. Spafford, C. F. Schryer, M. Mian, and L. Lingard, "Look who's talking: Teaching and learning using the genre of medical case presentations," J. Bus. Tech. Commun., vol. 20, no. 2, pp. 121-158, 2006.

[65] C. Spinuzzi, "Secret sauce and snake oil: Writing monthly reports in a highly contingent environment," Writ. Commun., vol. 27, no. 4, pp. 363-409, 2010.

[66] C. Spinuzzi, Tracing Genres Through Organizations: A Sociocultural Approach to Information Design. Cambridge, MA, USA: MIT Press, 2003.

[67] D. I. Steinberg, The Republic of Korea: Economic Transformation and Social Change. Boulder, CO, USA: Westview Press, 1989.

[68] T. Sung and D. Gibson, "Knowledge and technology transfer grid: Empirical assessment," Int. J. Technol. Manage., vol. 29, no. 3/4, pp. 216-230, 2005.

[69] J. Swarts, "Cooperative writing?: Achieving coordination together and apart," in Proc. 22nd Annu. Int. Conf. Design Commun., 2004, pp. 83-89.

[70] C. M. Tardy, "A genre system view of the funding of academic research," Writ. Commun., vol. 20, no. 1, pp. 7-36, 2003.

[71] S. E. Toulmin, The Uses of Argument. New York, USA: Cambridge University Press, 1969.

[72] L. Van Gemert and E. Woudstra, S. A. Amin and S. Fullerton, Eds., "Writing ISO-procedures: The use of sources of knowledge," in International Business Trends: Contemporary Readings. Cumberland, MD, USA: Academy of Business Administration, 1996, pp. 99-107.

[73] S. L. Vargo, "Market systems, stakeholders and value propositions: Toward a service-dominant logic-based theory of the market," Eur. J. Market., vol. 45, no. 1/2, pp. 217-222, 2011.

[74] S. L. Vargo, P. P. Maglio, and M. A. Akaka, "On value and value co-creation: A service systems and service logic perspective,” Eur. Manage. J., vol. 26, no. 3, pp. 145-152, Jun. 2008.

[75] L. Varpio, "Mapping the genres of healthcare information work: An interdisciplinary study of the interactions between oral, paper, and electronic forms of communication," , Ph.D. dissertation, Dept. English, University of Waterloo, Waterloo, ON, Canada, 2006.

[76] D. A. Winsor, "Learning to do knowledge work in systems of distributed cognition," J. Bus. Tech. Commun., vol. 15, no. 1, pp. 5-28, 2001.

[77] J.-E. (W.) Yusuf, "The entrepreneur-investor charismatic relationship: A dramaturgical approach," $J$. Enterprising Cult., vol. 19, no. 4, pp. 373-396, Dec. 2011.

[78] M. Zachry, C. Spinuzzi, and W. Hart-Davidson, "Researching proposal development: Accounting for the complexity of designing persuasive texts," in Proc. 24th Annu. Conf. Design Commun., 2006, pp. 142-148.

C. Spinuzzi, photograph and biography not available at the time of publication.

S. Nelson, photograph and biography not available at the time of publication.

K. S. Thomson, photograph and biography not available at the time of publication.

F. Lorenzini, photograph and biography not available at the time of publication.
R. A. French, photograph and biography not available at the time of publication.

Gregory Pogue, photograph and biography not available at the time of publication.

Sidney D. Burback, photograph and biography not available at the time of publication.

J. Momberger, photograph and biography not available at the time of publication. 